University of Nebraska - Lincoln

DigitalCommons@University of Nebraska - Lincoln

Biological Systems Engineering: Papers and

Publications

Biological Systems Engineering

December 2001

\title{
Will Voluntary and Educational Programs Meet Environmental Objectives? Evidence from a Survey of New York Dairy Farms
}

\author{
Gregory L. Poe \\ Cornell University \\ Nelson L. Bills \\ Cornell University \\ B. C. Bellows \\ Cornell University \\ Patricia Crosscombe \\ Cornell University \\ Richard K. Koelsch \\ University of Nebraska-Lincoln, rkoelsch1@unl.edu \\ See next page for additional authors \\ Follow this and additional works at: https://digitalcommons.unl.edu/biosysengfacpub \\ Part of the Biological Engineering Commons
}

Poe, Gregory L.; Bills, Nelson L.; Bellows, B. C.; Crosscombe, Patricia; Koelsch, Richard K.; Kreher, Michael J.; and Wright, Peter, "Will Voluntary and Educational Programs Meet Environmental Objectives? Evidence from a Survey of New York Dairy Farms" (2001). Biological Systems Engineering: Papers and Publications. 12.

https://digitalcommons.unl.edu/biosysengfacpub/12

This Article is brought to you for free and open access by the Biological Systems Engineering at DigitalCommons@University of Nebraska - Lincoln. It has been accepted for inclusion in Biological Systems Engineering: Papers and Publications by an authorized administrator of DigitalCommons@University of Nebraska Lincoln. 


\section{Authors}

Gregory L. Poe, Nelson L. Bills, B. C. Bellows, Patricia Crosscombe, Richard K. Koelsch, Michael J. Kreher, and Peter Wright 


\title{
Will Voluntary and Educational Programs Meet Environmental Objectives? Evidence from a Survey of New York Dairy Farms
}

\author{
Gregory L. Poe, Nelson L. Bills, B. C. Bellows, \\ Patricia Crosscombe, Richard K. Koelsch, \\ Michael J. Kreher, and Peter Wright
}

This paper presents the results from a survey of New York dairy farms that links manure management practices and farmer willingness to participate in voluntary environmental programs, focusing on those operations that are not automatically designated as Concentrated Animal Feeding Operations. A wide divergence is found between actual and recommended manure management practices on individual dairy farms (high), the apparent ability of farms to divert financial resources to environmental practices (mixed), and the willingness to participate in voluntary programs at various annual costs per cow (low). These findings have policy implications for the USDA/USEPA National Strategy for Animal Feeding Operations.

Gregory L. Poe-Associate Professor, Department of Applied Economics and Management, Cornell University and Visiting Fellow, Jackson Environmental Institute (JEI)/Centre for Social and Economic Research on the Global Environment (CSERGE), University of East Anglia, United Kingdom.

Nelson L. Bills - Professor, Department of Applied Economics and Management, Cornell University.

B.C. Bellows - Agricultural and Environmental Education Extension Associate, Department of Agricultural and Biological Engineering, Cornell University.

Patricia Crosscombe - doctoral candidate, Department of Education, Cornell University.

Richard K. Koelsch - Assistant Professor, Departments of Biological Systems Engineering and Animal Science, University of Nebraska-Lincoln.

Michael J. Kreher - Research Assistant, Department of Agricultural and Biological Engineering, Cornell University.

Peter Wright - Senior Extension Associate, PRO-DAIRY, Department of Animal Science, Cornell University. 
A nimal agriculture is presently at the forefront of state and federal agricultural environmental policy. According to United States Environmental Protection Agency (USEPA) documents, agriculture is the leading source of impaired river miles in New York and the United States, with animal operations recognized as a leading agricultural source of water contamination (USEPA; Cook). High profile spills from animal operations and the presumed linkage of animal waste practices to Cryptosporidium and Pfiesteria piscicida outbreaks have further elevated public concern about agriculture and water quality (Copeland and Zinn).

Responding to highly visible lawsuits against animal agriculture (e.g., Concerned Area Residents for the Environment v. Southview Farm, CA 2, No. 939229, 9/2/94) and the 1990 Coastal Zone Management Act Reauthorization Amendments (CZARA), New York established an Agricultural Environmental Management program in the mid-1990s to help farmers voluntarily meet environmental goals (Moore). At the national level, the recent United States Department of Agriculture (USDA)/USEPA Unified National Strategy for Animal Feeding Operations (AFOs) calls for all AFOs to implement Comprehensive Nutrient Management Plans (CNMPs) by 2009, relying on a blend of regulatory and voluntary programs (USDA/USEPA). In recent years, Congress has also demonstrated interest in livestock operations (e.g., the "Farm Sustainability and Animal Feedlot Enforcement Act" (HR 3232) and the "Animal Agriculture Reform Act" (S 1323)), while voters in individual states (e.g., Colorado) have passed referenda mandating greater regulations on large livestock operations.

Much public and industry attention has been devoted to "large" farms automatically designated by operation size to be Concentrated Animal Feeding Operations (CAFOs), ${ }^{1}$ and hence subject to Clean Water Act (CWA) permitting authority. However, the "vast majority of AFOs are small" with only $5 \%$ of the AFOs "expected to be regulated under existing CAFO regulations" (USDA/USEPA, pp. 9-10). For the remaining 95\% of operations, there is an explicit appeal to the farm sector's "ethic of land stewardship and sustainability" by relying on voluntary and educational efforts as the "principal approach to assisting owners and operators in developing and implementing site-specific CNMPs, and in reducing water pollution and public health risks associated with AFOs" (USDA/ USEPA, p. 10). The Unified National Strategy sets the "performance standard" objective that all AFOs, regardless of size, implement CNMPs by 2009.

Despite the elevated policy interest, little is known about actual manure management practices on dairy farms - especially those that do not satisfy the large CAFO designation. To quote the Unified National Strategy, "there is insufficient data on which to base an estimate of the number of AFOs that have unacceptable conditions" (USDA/USEPA, p. 16). Even less is known about farmers' attitudes and their willingness to participate in voluntary programs, a component that is critical to the success of national and state policy efforts.

In an effort to address these critical information gaps, and to develop a reference point for future policy analysis, we conducted a statewide mail survey of New York dairy farms that focused on documenting manure management practices and investigating farmer willingness to participate in voluntary agricultural environmental programs. This paper summarizes the results from this survey and discusses the policy implications of this re- 
search, with specific attention given to those dairy farms with less than 1,000 animal units (AU): those farms that do not satisfy the "large operation" definition and, hence, are not automatically designated as CAFO point sources of water pollution.

In the next section, we describe the survey. The third section documents the extent to which current practices on New York dairy farms correspond with desirable components of a CNMP - emphasizing the barnyard and wastewater handling elements that play a central role in the Unified National Strategy and focusing on farms with less than 1,000 AU. ${ }^{2}$ Evidence from this section suggests that current practices on many dairy farms deviate substantially from desired manure management practices. The fourth section provides the results from a series of questions directed at measuring farmer attitudes and willingness to participate in voluntary programs at varying costs. Documentation of such attitudes is essential to assessing whether voluntary AFO programs will be successful in attaining performance standards for the bulk of animal operations that do not satisfy the "large operation" CAFO definition. The willingness to participate results are also a novel application of contingent valuation to the agricultural industry, as past participation research has primarily focused on willingness to accept compensation in conservation programs (e.g., Purvis et al.; Lohr and Park, 1994, 1995; Cooper and Keim; Cooper and Osborn). Here we address the more realistic policy scenario for dairy manure management in the upcoming decade-what are expected participation rates at various implementation costs facing the farm? The final section summarizes the research and addresses the question, can voluntary and educational programs be expected to generate adequate participation to meet CNMP performance standards?

\section{Survey of Manure Management on New York Dairy Farms}

The survey consisted of a 16-page booklet, containing 41 questions, with sections on farm characteristics, manure management, handling manure, spreading manure, neighbor relations, and land-use issues. The survey was developed with input from agricultural economists, agricultural engineers, dairy specialists, and soil scientists at Cornell University, and water quality specialists, extension personnel, and federal and state agency staff throughout New York state. A pretest/focus group with 14 central New York farmers indicated only slight modifications to the pretest instrument. Drawing a random sample from a database of milk shipments in June 1995, 1,115 surveys were mailed to dairy farmers in upstate New York in summer and fall 1997. ${ }^{3}$ Following widely used mail survey procedures, with an advance mailing, an initial survey mailing, a thank you/reminder postcard, and two subsequent mailings, 470 completed surveys were returned. After accounting for no longer in dairy farming (83 obs.), bad addresses (37 obs.), and deceased ( 2 obs.), this represents a $47.5 \%$ adjusted response rate. Such a response rate is lower than the 50 to $70 \%$ standards widely adopted in contingent valuation research, but is higher than might be expected for such a controversial topic from an environmentally targeted industry.

Comparison of the returned surveys with data from New York Agricultural Statistics Service (NYASS) indicates that the regional distribution of the returned surveys corresponds closely with the actual distribution of New York dairy herds. However, the sam- 
ple distribution across herd size exhibits a slight upward bias. That is, relative to NYASS statistics, smaller herds with less than 100 cows are underrepresented in our survey responses relative to larger herds: the survey (and NYASS, 1997) distribution for 99 cows or less, 100 to 199 cows, and 200 plus cows was 71\% (81\%), 19\% (14\%), and 10\% (5\%), respectively. This apparent bias may reflect the age of our mailing list at the time of the survey. This list consisted of farms shipping milk in mid-1995, two years before the mail survey. If one assumes that the "no longer in dairy farming" group was largely composed of farms with smaller herd sizes, this could directly affect the size distribution of survey responses. It may also reflect a potential nonresponse bias by smaller farms. Unfortunately, we do not have the data to identify the probable source of this disparity. Consistent with the tendency towards larger herds, the average milk production per cow reported in the survey was a relatively high 17,927 lbs., which compares with the 1996 NYASS statewide average of $16,423 \mathrm{lbs}^{4}$

Responses to the survey were grouped according to actual and proposed federal water quality regulations affecting New York dairy farms. While the USDA/USEPA National Strategy automatically regulates large AFOs with more than 1,000 AU through permitting requirements, New York agricultural and environmental agencies are operating on the assumption that all dairy farms with more than 300 AU could be appropriate for CAFO permitting (CAFO Information Package, http://www.dec.state.ny.us/ website/dow ). Nevertheless, participation in the permitting process for farms with 301 to $1,000 \mathrm{AU}$ in New York is still regarded as voluntary. ${ }^{5}$ Correspondingly, for the purposes of this paper, "medium" farms are classified as those with 301 to 1,000 AU.6, 7 A second group of "small" farms with 101 to 300 AU will generally be exempt from CAFO requirements unless an individual farm is identified as a "significant contributor of pollution to the waters of the United States ... [and] pollutants are discharged from a man-made device or are discharged directly into waters passing over, across, or through the facility or otherwise come into direct contact with the confined animals" (USDA/USEPA). However, farms with 100 to 299 AU in New York will still need to conform with the 1990 CZARA manure management measures for storage facilities and nutrient management. The remaining "smallest" farms with less that 100 AU are presently exempt from federal water quality regulations, with the exception of the "significant contributor" clause indicated previously. As noted, however, even these smallest farms will be expected to have achieved the CNMP performance standard by 2009 . Using this classification, smallest, small, and medium farms comprise $41 \%, 49 \%$, and $10 \%$ of the completed surveys, respectively.

\section{Components of the Comprehensive Nutrient Management Plan}

While the specific practices will need to be determined at the individual farm level, the USDA/USEPA National Strategy has identified several components that should be accounted for in a CNMP. Here we investigate four central components of such plans across herd sizes: manure handling, storage, land application of manure, and record keeping. 


\section{Manure Handling}

The siting and barnyard management practices are a central feature of any CNMP. Figure 1 demonstrates that for many farms, the use of barnyards and barnyard location relative to surface water would be classified as an environmental risk: $14 \%$ of farms have surface water within the "fencing of the barnyard" and an additional 32\% of the barnyards are within 300 feet of the nearest downhill surface water. While CNMP barnyard location requirements have not been specified, the farms with surface water running through their barnyards clearly have a fundamental problem, and those barnyards within 300 feet are likely be scrutinized by environmental agencies. Figure 1 also demonstrates an observation that carries through the remainder of this subsection, that environmental risks associated with manure management practices do vary substantially and significantly across herd sizes. Notably, medium farms tend to have lower reliance on barnyards $(p<0.001){ }^{8}$ and thus are less subject to run-on and runoff concerns.

Figures 2 and 3 similarly demonstrate that management of animal holding areas varies across farm size. Smaller farms tend to have adopted fewer run-on control practices (e.g., gutters and natural topography, $p<0.001$ ). They also tend to have less investment in controlling runoff $(p<0.001)$, with only $15 \%$ providing some sort of desirable runoff con-

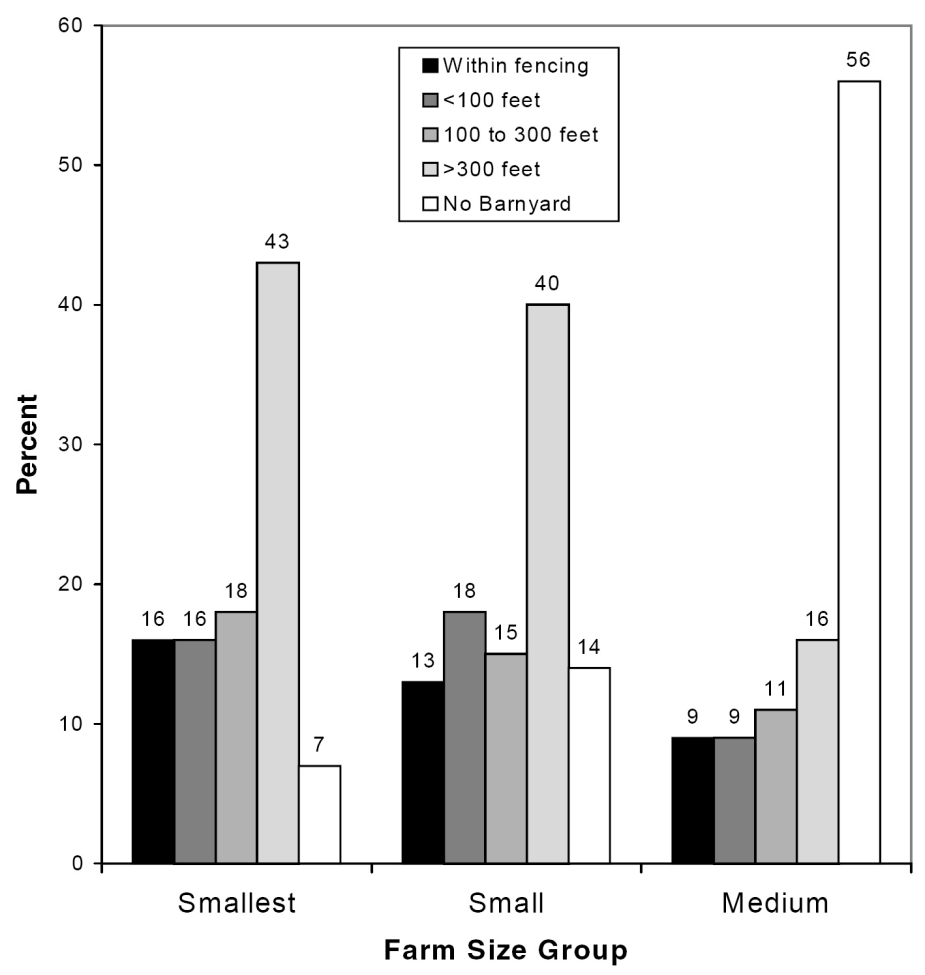

Figure 1. Percent of farms by proximity to downhill surface water and farm size. 


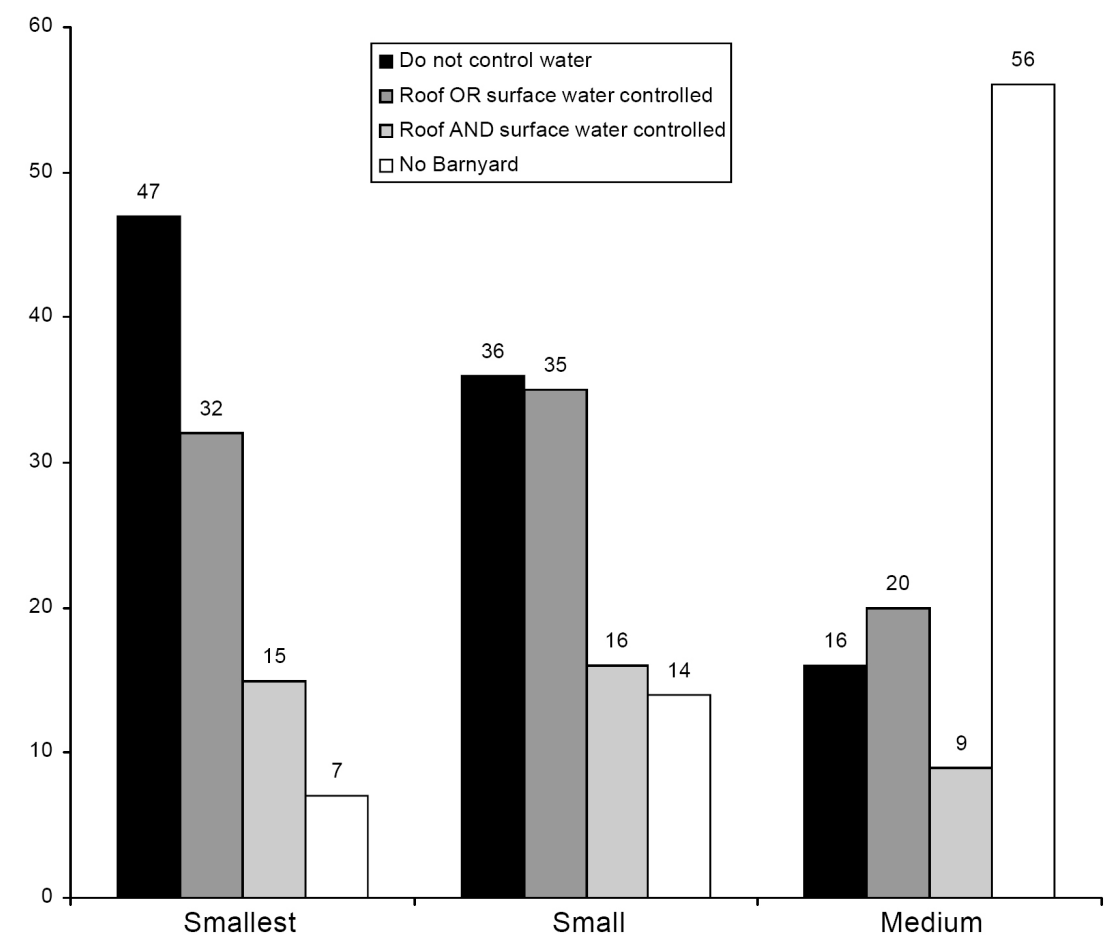

Figure 2. Percent of farms controlling roof and barnyard surface water by farm size.

trol. Again, a large component of this disparity in distributions across groups is attributed to the relatively limited use of barnyards on larger farms. In addition to barnyard location, animals can have direct access to surface water while pasturing or in transit. This form of direct contact also varies by herd size $(p=0.052)$ with $43 \%, 51 \%$, and $60 \%$ of medium, small, and smallest farms indicating that their "livestock have direct access to surface water or cross a stream to get to pasture."

\section{Storage}

Adequate manure storage is a critical issue in northern states such as New York, where avoiding saturated and frozen ground is difficult without 180-day storage capacity. As demonstrated in table 1 , average storage capacity is higher on medium farms $(p=0.011)$ and the average number of days in a year in which manure is spread is lower $(p<0.001)$ than that for the other size groups. Yet, only $22 \%$ of medium farms have storage capacity exceeding 180 days. And reliance on daily spreading prevails in all size groups, with a mean of 263 days per year across all farm sizes. To a large extent, the observed deviation in storage and spreading across head sizes is due to a greater reliance of larger farms on liquid manure handling systems $(p<0.001)$. 


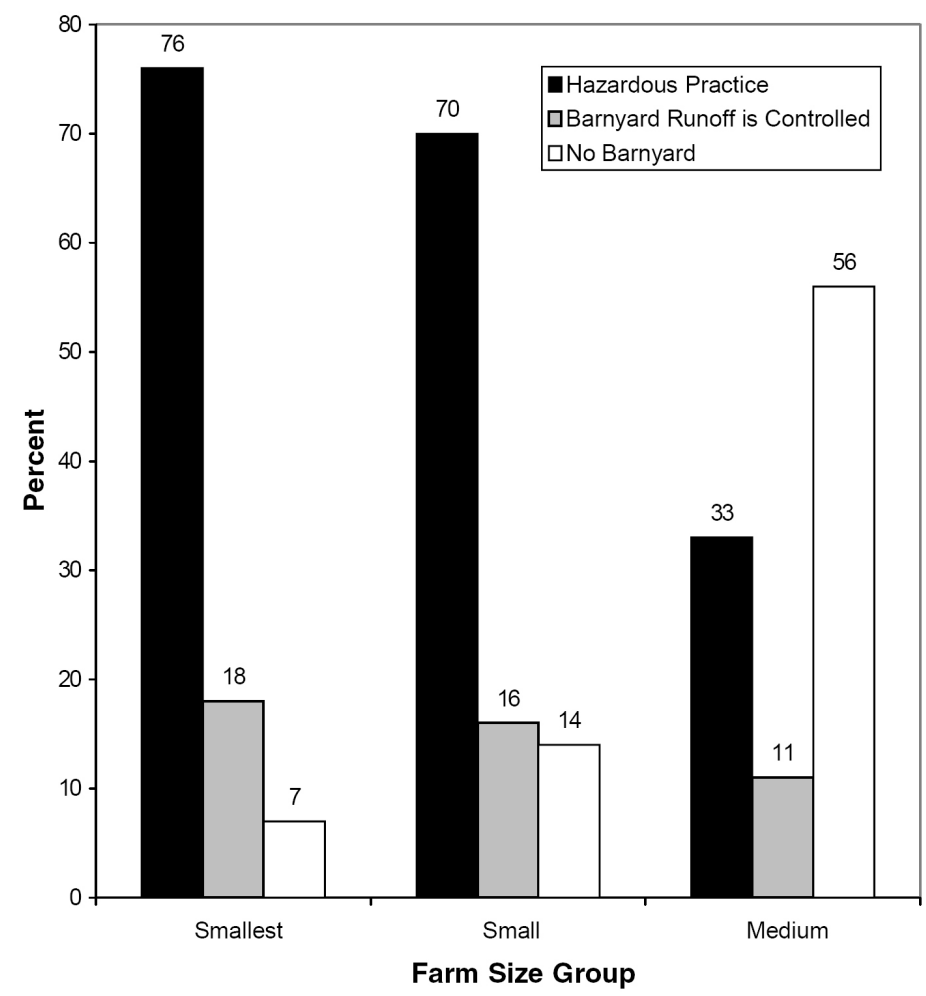

Figure 3. Percent of farms controlling barnyard runoff by farm size.

\section{Land Application of Manure}

According to the USDA/USEPA National Strategy, "land application is the most common, and usually the most desirable method of utilizing manure" (USDA/USEPA, p. 8). From the perspective of potential land use, the average New York dairy farm in this survey has more than an adequate amount of land for applying manure. A commonly used

Table 1. Manure handling and storage

\begin{tabular}{lccc}
\hline & Smallest & Small & Medium \\
\hline Percent of farms that handle manure as a liquid or slurry & 94 & 74 & 14 \\
Percent of farms by maximum days of manure storage & & & \\
No storage & 58 & 46 & 39 \\
Less than 60 days & 87 & 77 & 58 \\
Less than 180 days & 93 & 91 & 78 \\
Average number of days manure is spread per year & 274 & 271 & 185 \\
\hline
\end{tabular}




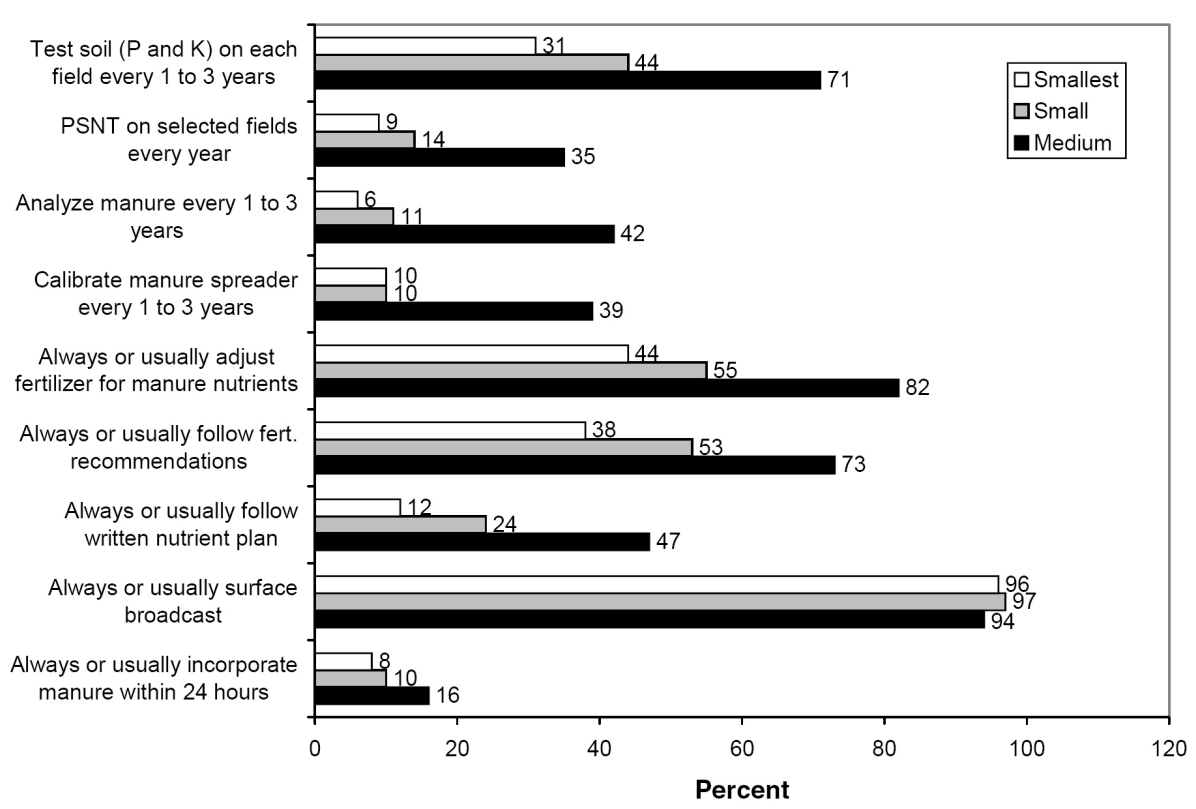

Figure 4. Percent of farms implementing select nutrient management practices by farm size.

threshold for land application is 0.5 acre/AU, which is greatly exceeded by all farm size groups, with medium, small, and smallest farms having 1.85, 2.36, and 2.77 acres/ AU ( $p$ $<0.001$ ).

In spite of this potential, New York dairy farms as a whole do not appear to have adopted recommended practices in terms of soil and manure testing, calibration, accounting for manure in nutrient management planning, and application practices. As demonstrated in figure 4, a greater proportion of medium farms have implemented recommended nutrient management practices, with significance levels across herd sizes generally less than $0.1 \%$. The exceptions to this trend are the proportion of respondents who always or usually "surface broadcast manure with a spreader" $(p=0.676)$ and the proportion who always or usually "incorporate manure within 24 hours of application" $(p=0.206)$. While a greater proportion of medium farms have adopted recommended practices, it is evident that there is still a wide gap between existing practices and practices likely to be required by a CNMP for all size groups.

\section{Record Keeping}

Livestock operators should "keep records that indicate the quantity of manure produced and how the manure was utilized, including when, where, and amount of nutrients applied" (USDA/USEPA, p. 9). However, only 73\% of medium farms, $53 \%$ of small farms and $38 \%$ of smallest farms indicated that they maintain records $(p<0.001)$.

Taken together, the above findings suggest that the New York dairy industry will be substantially challenged by existing and proposed water quality legislation in the sense 
that actual practices tend to deviate from those associated with recommended components of a CNMP. Moreover, the degree of noncompliance varies significantly across herd sizes.

\section{Neighbor Relations, Farmer Attitudes on Land Use, and Willingness to Participate}

In addition to actual practices, a number of questions were posed pertaining to land use issues and neighbor relations. We also described a voluntary agricultural environmental program similar to those proposed in New York, and elicited willingness to participate in this program using contingent valuation type questions.

\section{Neighbor Relations}

With respect to neighbor relations, anecdotal reports would suggest that the typical livestock operation is under siege from lawsuits and neighbor complaints. This does not appear to be the case for the New York dairy industry: over 63\% of farms had not received any "complaints from neighbors or local public officials in the last five years," with significant variation across herd size: 39\%,58\%, and 76\% for medium, small, and smallest farms, respectively. For dairy farms that experienced complaints, the following were categories of complaints and associated percentages of total complaints: odors $(42 \%)$, roadway spills $(26 \%)$, water pollution $(17 \%)$, farm traffic $(14 \%)$, chemical use (11\%), flies/insects $(10 \%)$, noise $(7 \%)$, dust $(7 \%)$. Only odor complaints were significantly different across farm size: $66 \%, 42 \%$, and $25 \%$ for medium, small, and smallest farms $(p<0.001)$. This focus on odors rather than water quality is consistent with "management practices" complaints to the New York State Department of Agriculture and Markets, but deviates from the regulatory focus on water quality (Rudgers; Bills and Cosgrove).

\section{Farmer Attitudes on Land Use Issues}

Likert scale responses to a series of opinion questions indicate that, in contrast with popular beliefs and property rights implied by a regulatory approach to controlling agricultural pollution, farmers generally do not believe that they cause water quality problems or that they should have to pay for installing water pollution control practices on current operations (see table 2). Response patterns to these questions tend not to differ by herd size, with consistent response patterns for individual farms being a source of water pollution (Q27A: $p=0.412)$, whether they would be able to stay in business if they had to incur substantial environmental costs (Q27B: $p=0.134)$, and whether farmers should have to pay for environmental practices when they expand operations (Q27D: $p=0.221$ ). However, a greater proportion of small farm operators felt that they should not have to pay for installing water pollution practices on current operations (Q27C: $p=0.042)$. Irrespective of property right beliefs, many farmers would be "able to pay" substantial environmental costs, with $27 \%$ indicating that they would "stay in the dairy business" at a cost of \$50/cow/year. Participants in a 1999 New York State Bankers Association seminar suggested that at least half of the "neutral" respondents would also be able to stay in the business. 
Table 2. Distribution (\%) of responses to agricultural environmental opinion questions.

\begin{tabular}{|c|c|c|c|c|c|c|}
\hline & $\begin{array}{c}\text { Farm } \\
\text { Size }\end{array}$ & $\begin{array}{l}\text { Strongly } \\
\text { Disagree }\end{array}$ & & Neutral & & $\begin{array}{l}\text { rongly } \\
\text { Agree }\end{array}$ \\
\hline $\begin{array}{l}\text { Q27A. In a typical year, manure } \\
\text { and barnyard runoff is not a water } \\
\text { pollution problem from my farm }\end{array}$ & $\begin{array}{c}\text { All } \\
\text { Farms }\end{array}$ & 7 & 6 & 24 & 31 & 32 \\
\hline $\begin{array}{l}\text { Q27B. If my net returns declined } \\
\text { by } \$ 50 \text { per cow per year, I would } \\
\text { not stay in the dairy business }\end{array}$ & $\begin{array}{c}\text { All } \\
\text { Farms }\end{array}$ & 15 & 12 & 34 & 13 & 26 \\
\hline $\begin{array}{l}\text { Q27C. Farmers should not have } \\
\text { to pay for installing water } \\
\text { pollution control practices on } \\
\text { current operations }\end{array}$ & $\begin{array}{l}\text { Smallest } \\
\text { Small } \\
\text { Medium }\end{array}$ & $\begin{array}{l}6 \\
8 \\
4\end{array}$ & $\begin{array}{r}6 \\
13 \\
15\end{array}$ & $\begin{array}{l}34 \\
31 \\
35\end{array}$ & $\begin{array}{l}13 \\
15 \\
25\end{array}$ & $\begin{array}{l}41 \\
34 \\
21\end{array}$ \\
\hline $\begin{array}{l}\text { Q27D. Farmers should not have } \\
\text { to pay for installing water } \\
\text { pollution control practices when } \\
\text { they expand their operation }\end{array}$ & $\begin{array}{c}\text { All } \\
\text { Farms }\end{array}$ & 20 & 24 & 30 & 11 & 16 \\
\hline
\end{tabular}

\section{Willingness to Participate}

It is clear from the above that the manure management practices on many New York dairy farms deviate substantially from what will be expected under CNMPs. The cost of meeting these CNMPs is expected to vary widely across farms, and may be quite substantial in some instances. For example, based on extensive field experience, Cornell Cooperative Extension estimates that, in addition to per farm preparation costs, controlling barnyard runoff will cost $\$ 1,000$ to $\$ 500,000$ per farm. Nutrient management plans will be expected to break even. In recent years, the New York Agricultural Non-Point Source Grant Program has provided funds to individual farms to address manure management issues, with grants ranging from $\$ 2,155$ to $\$ 419,050$ for farms with over 300 AU (Wildeman). The USDA estimated average cost per cow per year to meet 1990 Coastal Zone Management Act requirements to range from \$17.01 to \$34.63 (Heimlich and Barnard). Taken together, the evidence suggests that implementation of CNMPs would be a costly endeavor on many farms.

New York's efforts to pursue a voluntary program and the voluntary/ regulatory mix proposed in the USDA/USEPA National Strategy raises the critical question of how many farmers would actually participate in voluntary programs. Here we use a "contingent valuation" survey method to estimate participation levels at different costs to the farmer. This technique has been widely used in the last three decades to place economic values on environmental goods (Mitchell and Carson; Loomis). Several studies have also applied this technique to valuing positive (open-space) and negative (water contamination) agricultural externalities (see Poe for a review). Recently economists have adapted this survey method to estimate the likelihood of participation in conservation programs at various payments to the farmer (e.g., Purvis et al.; Lohr and Park, 1994, 1995; Cooper and Keim; 


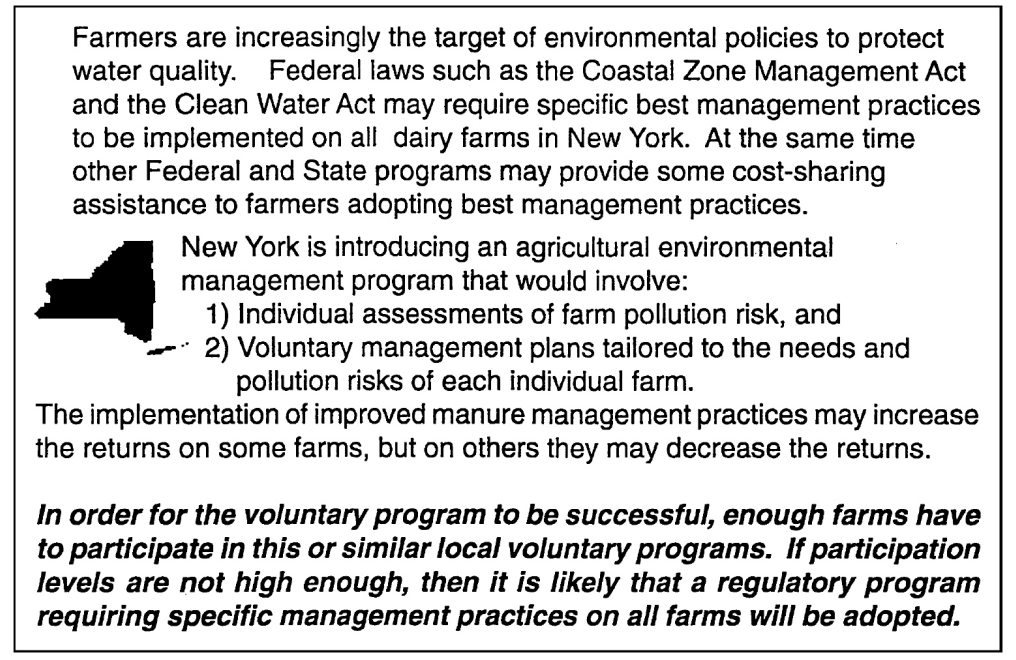

Figure 5. Contingent valuation scenario

Cooper and Osborn). Such a willingness to accept framing is not consistent with present water quality efforts. Rather, given limited funding and the large number of operations, a willingness to participate at various costs format is more appropriate to the current AFO and water quality situation.

Figure 5 provides the text of the contingent participation scenario corresponding with the current policy situation. In creating this question, effort was taken to develop a concise half-page scenario that closely resembles New York's voluntary Agricultural Environmental Management (AEM) program. Two central features of the AEM and CNMP program, individual assessments of farm pollution risk and voluntary management plans tailored to the needs and pollution risks of each individual farm, were explicitly mentioned. Corresponding to policy expectations that some minimum level of participation would be required for the program to be classified as a success, the need for "high" participation levels was emphasized.

Given this scenario, farmers were asked: "If you determined that the cost to implement manure management practices on your farm would be one of the following amounts each year, would you participate in the voluntary program?" Using a multiple bounded format described in Welsh and Poe, the dollar amounts that each respondent was asked to consider included 0 cents, 10 cents, 25 cents, 50 cents, \$1.00, \$2.00, \$5.00, \$10.00, \$25.00, $\$ 50.00, \$ 100.00$, and $\$ 200.00$ per cow per year. For each dollar amount, respondents indicated their likelihood of participation in the program, with response options including "I would definitely participate," "I would probably participate," "not sure," "I would probably not participate," and "I would definitely not participate."

The range of "cost per cow" dollar values was determined by first estimating an upper bound of $\$ 100$ on possible costs and then doubling this value to avoid any truncation effects on willingness to participate (WTP). ${ }^{9}$ A lower bound of zero was used to capture 
Table 3. Distribution of participation responses across selected dollar values - percent (cumulative percent).

\begin{tabular}{lccrrr}
\hline & $\begin{array}{c}\text { Definitely } \\
\text { Participate }\end{array}$ & $\begin{array}{c}\text { Probably } \\
\text { Participate }\end{array}$ & Not Sure & $\begin{array}{c}\text { Probably Not } \\
\text { Participate }\end{array}$ & $\begin{array}{c}\text { Definitely Not } \\
\text { Participate }\end{array}$ \\
\hline$\$ 0.00$ & 58 & 20 & 14 & 4 & 4 \\
& & $(78)$ & $(92)$ & $(96)$ & $(100)$ \\
$\$ 0.10$ & 44 & 23 & 15 & 6 & 13 \\
& & $(67)$ & $(82)$ & $(87)$ & $(100)$ \\
$\$ 0.50$ & 37 & 18 & 18 & 10 & 17 \\
& & $(55)$ & $(73)$ & $(83)$ & $(100)$ \\
$\$ 5.00$ & 12 & 12 & 24 & 16 & 35 \\
$\$ 50.00$ & 2 & $(25)$ & $(49)$ & $(65)$ & $(100)$ \\
& 2 & 2 & 12 & 16 & 68 \\
& & $(3)$ & $(16)$ & $(32)$ & $(100)$ \\
\hline
\end{tabular}

"no net loss in farm returns" programs like that used in the New York City watershed (McGuire).

Based on previous contingent valuation validity research, our analysis focuses on the "probably participate" (or higher) responses (Poe et al.; Blumenschein et al.). As indicated in table 3, responses at this level or higher are approximately $78 \%$ at $\$ 0$, a proportion which is only slightly exceeded by participation rates in the complete costsharing program in the New York City watershed. However, the "probably participate" responses fall below the median by $\$ 5$ per cow, and approach 3\% at $\$ 50$ and above. This latter figure contrasts substantially with the $27 \%$ of the respondents who indicated that they would be likely to stay in business if they had to pay $\$ 50$ per cow per year; thus there appears to be a broad discrepancy between "ability to pay" and "willingness to participate." Such a discrepancy is consistent with the sequence of producer denial that has characterized past agricultural environmental issues (Daily) and the economic notion of free-riding.

WTP is likely to be associated with many factors, including the cost of participation, herd size, farmer attitudes, and socioeconomic characteristics. Due to the large dimensions of the response matrix $(12 \times 5)$ and the need to control for various factors simultaneously, contingency table analyses, as used in the rest of this article, are neither appropriate nor informative. Instead, a multiple bounded approach analogous to the maximum likelihood interval modeling approach used for payment card data was used to model the "probably participate" response function (see Welsh and Poe). Letting $X_{i L}$ be the maximum amount that an individual respondent (i) indicates that he/she would "probably participate" and $X_{i U}$ be the lowest amount that an individual was "unsure" or lower about participation, $W T P_{i}$ lies somewhere in the switching interval $\left[X_{i L^{\prime}} X_{i U}\right]$. Let $F\left(X_{i} ; \beta\right)$ denote a statistical distribution for $W T P_{i}$ with parameter vector $\beta$. The probability that an individual will "probably participate" at specific dollar amount $X$ is $1-F\left(X_{i} ; \beta\right)$. The prob- 
ability that $W T P_{i}$ falls between any two cost levels is $F\left(X_{i U^{\prime}} ; \beta\right)-F\left(X_{i L^{\prime}} ; \beta\right)$ resulting in the corresponding log-likelihood function

$$
\ln (L)=\sum_{i=1}^{n} \ln \left[F\left(X_{i U} ; \beta\right)-F\left(X_{i L} ; \beta\right)\right] .
$$

where $F\left(X_{i} ; \beta\right)$ is defined to be the standard logistic function for the cumulative distribution function

$$
F(X ; \beta)=1 /\left(1+\mathrm{e}^{-(a+b X)}\right)
$$

and $a$ and $b$ are coefficients to be estimated. These estimates were then converted to WTP functions following methods detailed in Cameron (1988, 1991). Combined, these statistical analyses allow us to estimate a "regression" function relating WTP to other variables reported in the questionnaire.

In estimating these WTP regressions, the dollar per cow value was multiplied by the number of milking and dry cows reported in the survey in order to directly estimate WTP as a function of total, as opposed to per cow, farm costs. As such, each respondent faces a unique set of dollar values in considering his WTP. In the simplest case, we estimated WTP as a function of the dollar value and the herd size. The resulting regression coefficients were wo $^{10}$

$$
\mathrm{WTP}=-96.46+222.97 \mathrm{D} 101300+968.83 \mathrm{D} 3011000
$$

in which the intercept was not significantly different from zero but both the herd size slope shifters were significant at the 5\% level or higher (see Model 1 in table 4). Holding everything else constant, this estimated function indicates that the average smallest farms would not be willing to participate in this type of voluntary program even if it did not reduce their net returns. In contrast, the average small farm would probably participate at a cost of $\$ 126.51(=-96.46+222.97)$ per annum. Similarly, these estimates indicate that the average medium dairy farm would participate at a cost of $\$ 872.39(=-96.46+968.83)$ per annum. Accounting for the size distribution across farms, the overall average willingness to participate is $\$ 133$.

Other covariates were introduced into the model in an effort to account for farmer and farm characteristics that are correlated with WTP and to examine the construct validity of farmer responses. These additional variables are evaluated in Models 2 to 4 in table 4, which hold the number of observations constant across models at the level associated with Model 3, the most complete model: Model 2 uses the limited set of covariates in Model 1, indicating that the restricted number of observations provides similar results; Model 3 includes the most complete set of covariates; and Model 4 excludes those Model 3 covariates (D101300, Q27C, and Inoper10) that were not significant at the 20\% level. While these excluded variables were not individually significant, the estimated coefficients demonstrate the expected sign: whether or not farmers believed that they should have to pay for installing water pollution control practices on current operations (Q27C) was not statistically significant, a finding that seems to contradict the widespread "property rights" be- 
Table 4. Estimated multiple bounded coefficients, "probably yes" models.

\begin{tabular}{|c|c|c|c|c|c|c|c|}
\hline Variable & Description & $\begin{array}{c}\text { Mean } \\
\text { Value }[\mathrm{n}]\end{array}$ & $\begin{array}{l}\text { Sign } \\
\text { Exp. }\end{array}$ & Model 1 & Model 2 & Model 3 & Model 4 \\
\hline Constant & 1 & 1 & n.a. & $\begin{array}{l}-96.46 \\
(78.41)\end{array}$ & $\begin{array}{l}-42.12 \\
(83.11)\end{array}$ & $\begin{array}{c}-78.00 \\
(424.23)\end{array}$ & $\begin{array}{c}-45.93 \\
(385.68)\end{array}$ \\
\hline D101300 & $\begin{array}{l}\text { Binary: } 101 \text { to } \\
300 \mathrm{AU}=1\end{array}$ & $\begin{array}{l}0.51 \\
{[357]}\end{array}$ & $?$ & $\begin{array}{l}222.97 \\
(100.38)^{* *}\end{array}$ & $\begin{array}{c}196.57 \\
(105.80)^{*}\end{array}$ & $\begin{array}{c}89.34 \\
(103.33)\end{array}$ & \\
\hline D3011000 & $\begin{array}{l}\text { Binary: } 301 \text { to } \\
\text { 1,000 AU = } 1\end{array}$ & $\begin{array}{c}0.12 \\
{[357]}\end{array}$ & $?$ & $\begin{array}{l}968.63 \\
(186.15)^{* * *}\end{array}$ & $\begin{array}{l}942.75 \\
*(192.82)^{* * *}\end{array}$ & $\begin{array}{l}596.29 \\
*(182.45)^{* * *}\end{array}$ & $\begin{array}{l}551.83 \\
(166.36)^{* * *}\end{array}$ \\
\hline Q27A & $\begin{array}{l}1-5 \text { scale: Farm } \\
\text { is not a water } \\
\text { pollution problem }\end{array}$ & $\begin{array}{l}3.77 \\
{[357]}\end{array}$ & - & & & $\begin{array}{l}-99.30 \\
(42.27)^{* *}\end{array}$ & $\begin{array}{l}-99.98 \\
(42.11)^{* *}\end{array}$ \\
\hline Q27B & $\begin{array}{l}1-5 \text { scale: Not able } \\
\text { to pay } \$ 50 \text { per cov }\end{array}$ & $\begin{array}{l}\text { le } 3.16 \\
\text { ow [325] }\end{array}$ & - & & & $\begin{array}{l}-80.88 \\
(37.02)^{* *}\end{array}$ & $\begin{array}{l}-95.09 \\
(35.24)^{* * *}\end{array}$ \\
\hline Q27C & $\begin{array}{l}\text { 1-5 scale: Farmers } \\
\text { should not have t } \\
\text { pay for installing } \\
\text { practices, current } \\
\text { operations }\end{array}$ & $\begin{array}{l}\text { rs } 3.61 \\
\text { to [325] } \\
\text { it }\end{array}$ & - & & & $\begin{array}{l}-21.01 \\
(40.72)\end{array}$ & \\
\hline No-Complain & $\begin{array}{l}\text { Binary: no. of } \\
\text { complaints from } \\
\text { neighbors or local } \\
\text { officials in last fiv } \\
\text { years }=0\end{array}$ & 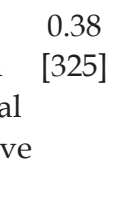 & + & & & $\begin{array}{l}160.56 \\
(98.19)\end{array}$ & $\begin{array}{l}170.22 \\
(98.27)^{*}\end{array}$ \\
\hline Inoper10 & $\begin{array}{l}\text { Binary: farmer, } \\
\text { family or partner } \\
\text { expects to be in } \\
\text { operation in } \\
10 \text { years }=1\end{array}$ & $\begin{array}{cc} & 0.62 \\
r \quad[325]\end{array}$ & + & & & $\begin{array}{c}98.04 \\
(103.57)\end{array}$ & \\
\hline Age & Age in years & $\begin{array}{l}48.07 \\
{[325]}\end{array}$ & - & & & $\begin{array}{l}-6.79 \\
(4.38)\end{array}$ & $\begin{array}{l}-7.33 \\
(4.25)^{*}\end{array}$ \\
\hline Milk & $\begin{array}{l}\text { Lbs milk per cow } \\
\text { per year, actual } \\
\text { or estimated from } \\
\text { daily milk produc }\end{array}$ & $\begin{array}{l}\text { v } \begin{array}{l}17,949 \\
{[325]}\end{array} \\
m \\
\text { action }\end{array}$ & $?$ & & & $\begin{array}{l}0.06 \\
(0.02)^{* * *}\end{array}$ & $\begin{array}{l}0.06 \\
(0.02)^{* * *}\end{array}$ \\
\hline$k$ & $\begin{array}{l}\text { Scale parameter } \\
\text { as defined in } \\
\text { Cameron (1988) }\end{array}$ & n.a. & & $\begin{array}{l}516.32 \\
(45.36)^{* * *}\end{array}$ & $\begin{array}{l}522.15 \\
* \quad(47.49)^{\star * *}\end{array}$ & $\begin{array}{l}479.53 \\
(36.01)^{\star * *}\end{array}$ & $\begin{array}{l}481.53 \\
(36.03)^{* * *}\end{array}$ \\
\hline \multicolumn{4}{|l|}{$n$} & 357 & 325 & 325 & 325 \\
\hline \multicolumn{4}{|c|}{$-2 \times \log$ likelihood } & 1875.49 & 1715.20 & 1675.98 & 1677.98 \\
\hline
\end{tabular}

Note: ${ }^{*}, * * * *$ denote 10,5 , and $1 \%$ significance levels, respectively. 
lief that farms should not have to pay to install environmental practices on their farms; farmer expectations about whether they would be in business in the next 10 years was positively correlated with WTP but was not statistically significant. Because of correlation in responses between these and other covariates, the exclusion of these nonsignificant covariates raises the significance of the remaining covariates in the "short" Model 4.

Notably, as expected, WTP is positively correlated with the belief that one's farm is not a water pollution problem. This finding is important, because it suggests some potential for an educational role in agricultural environmental policy in the sense that WTP would be expected to rise if farmers could be convinced that their farm contributes to water pollution problems. This point is further explored in the discussion section of this paper. In addition, it was found that the ability to pay, as measured by the response to Q27B concerning the farmer's assessment of staying in business if additional environmental costs were $\$ 50$ per cow, was positively correlated with WTP. Such a report supports the intuitive argument that those farms which are more economically viable will have a higher WTP. WTP was also significantly and positively correlated with production per cow, suggesting that more intense milk production management may carry over to willingness to invest in manure management. Community pressures also appear to exert an influence on WTP, as farms that had received complaints from neighbors or local officials in the last five years had a higher WTP. The age of the farmer was negatively correlated with participation. Overall, the models strongly conform with prior expectations, indicating that WTP does vary systematically across farmers and suggesting that these contingent participation measures demonstrate construct validity.

In summary, stated WTP behaves in a manner consistent with prior expectations, and estimated participation rates in a voluntary pollution control program at various costs to farmers is much lower than the expected costs of meeting CNMPs facing many farms. This latter finding should not be interpreted as implying that farmers have a low environmental ethic. Many farmers may simply have reached their own environmental equilibrium, in which they are undertaking practices as they seem fit. As such, they may be reluctant to contribute additional funds simply to meet the demands of the broader population. Such a conclusion may be supported by the observation that a relatively small proportion of farmers believe that they are presently contributing to water pollution in a typical year.

\section{Summary and Discussion}

This research provides key insights into the degree of nonconformance with recommended CNMP best management practices, and the likelihood of voluntary participation to meet stated agricultural environmental objectives. Such research is critical because the great majority of livestock operations in New York, and the rest of the country, fall below the regulatory AU threshold associated with the CWA. Compliance with recommended practices on those farms that do not exceed this threshold will rely on voluntary and educational activities.

The data from this survey indicate that there is a substantial gap between actual and recommended nutrient management practices for all dairy farm size groups. Many 
Table 5. Mean willingness to participate values (\$) by AU category and response to Q27A: In a typical year, manure and barnyard runoff is not a water pollution problem from my farm $(\mathrm{n}=357$, probably participate model)

\begin{tabular}{lcrcrr}
\hline & Strongly & & & $\begin{array}{c}\text { Strongly } \\
\text { Agree }\end{array}$ \\
\hline Lisagree & & Neutral & & $\leq 0$ \\
101 to 300 AU & 433 & 321 & 208 & 96 & $\leq 0$ \\
301 to 1,000 AU & 1,170 & 1,058 & 946 & 833 & 721 \\
\hline
\end{tabular}

of these gaps are fundamental. For example, $14 \%$ of farms have surface water running through their barnyards and less than $10 \%$ of farms have 180 days storage. It is clear from these data that farms will have to incur a range of costs to meet performance objectives stated in the USDA/USEPA National Strategy. On some farms, these added costs will be negligible. But on others, particularly those which will need to relocate their barnyards or install storage facilities, these costs may be substantial.

Given these data, the critical question to ask for farms outside the CWA regulatory scope is, can voluntary and educational programs be expected to generate adequate participation to meet CNMP performance standards? The answer to this question is strongly in the affirmative if adequate cost sharing is provided: over $78 \%$ of respondents indicated that they would participate in such a program if it was $100 \%$ cost shared. Yet, once even nominal costs are imposed, participation levels drop dramatically in a manner that is consistent with the economic notion of free-riding that has prevailed since Samuelson's seminal article on public goods. As such, the results provided thus far suggest that attaining the CNMP performance standard will be difficult at best.

Some additional insight on this issue is gained by disaggregating the data as in the matrix provided in table 5. The rows in this table correspond with herd sizes used throughout this manuscript. The columns indicate different levels of agreement with Q27A, "In a typical year, manure and barnyard runoff is not a water pollution problem from my farm." Values within each cell are derived from the following regression results, where the variables and the significance levels correspond to those used in table $4:{ }^{11}$

$$
\begin{aligned}
& \mathrm{WTP}=336.83-112.29 \mathrm{Q} 27 \mathrm{~A}+208.30 \mathrm{D} 101300 \\
& (172.63)^{*} \quad(41.17)^{* * *} \quad(99.28)^{* *} \\
& +945.60 \mathrm{D} 3011000+508.01 k \text {. } \\
& (181.29)^{* * *} \quad(42.91)^{* * *}
\end{aligned}
$$

As expected from the sign of the coefficients, the predicted values at which the median farm would participate rise with greater disagreement that "manure and barnyard runoff is not a water pollution problem from my farm" and with herd size grouping. That is, moving within a farm-size group along a row from right to left suggests that, ceteris pari- 
bus, WTP rises with the belief that one's farm contributes to water pollution. Thus, if educational programs were able to shift all farms into the "strongly disagree" category (i.e., recognition that runoff from their farm contributes to water pollution), average participation would be expected to rise. However, under the ceteris paribus conditions, predicted participation levels still fall short of the expected costs on many farms, with maximum values of $\$ 225, \$ 443$, and $\$ 1,170$ for the smallest, small, and medium farms, respectively.

It is possible that such ceteris paribus conditions are not appropriate when discussing the effects of education. Drawing an analogy to demand curves, it can be argued that education does not simply move perceptions along a given "environmental demand curve." Rather the impact of education is to shift the environmental demand curve outwards. We acknowledge that such a shift is plausible, and, indeed, we desire it to be true. Yet behaviors are slow to change, and despite our wishes, we adopt a more pessimistic stance that there is a strong status quo effect in the bulk of the farm community that works against such a shift in demand. In Bayesian terms, strong weight is given to the priors or current beliefs. Along these lines we maintain that outward movement in willingness to participate will occur slowly at best.

Given our data and estimated participation functions, we believe that our results raise a considerable challenge to present efforts that rely on educational programs and voluntary participation in order to meet stated performance standards on the majority of AFOs not directly subject to CWA regulations. Based on our analysis, it appears that agricultural environmental policy in New York and elsewhere will need to extend or move beyond the present voluntary program approach to meet water quality objectives. Either substantial additional resources or an extension of regulations will be needed to accomplish CNMP performance standards by 2009.

In addition, although we do not offer reasons for deviations in practices across the policy-relevant farm size groupings that we used in our analyses, it is clear from our data that different herd size groups exhibit systematically different levels of conformity with CNMP expectations. As such, our results suggest that efficient policy design will need to explicitly account for farm size. It is also clear that basic policy-relevant research is needed to develop an understanding of why these differences across farm size are observed.

\section{Acknowledgments}

Support for this project was provided by Cornell University's Statewide Program Committee grants, the Cornell University Water Resources Institute, Hatch Project \# 121-416, and Cornell Cooperative Extension. We are indebted to Jane Maestro-Scherer and Survey Intelligence, Inc. for their work on the design and implementation of the survey, respectively. Any errors, however, remain our responsibility.

\section{Endnotes}

1 The CWA gives the USEPA the authority to regulate point source discharges, including CAFOs, into the waters of the United States through the National Pollution Discharge Elimination System (NPDES) permitting program. In order for an AFO to be considered a CAFO, a facility must meet the NPDES definition [40 CFR 122.23(b)(1)] of an AFO: a lot or facility where animals have been, are, or will be stabled or confined and fed or maintained for a total of 45 days or more in any 12 month period and 
where crops, vegetation, forage growth, or post harvest residues are not sustained over a growing season. Under the NPDES program, an AFO is automatically a CAFO if more than 1,000 animal units are confined at the facility [40 CFR Part 122 Appendix B]. For dairy, this is approximately equal to 700 mature cows. An AFO may also be designated as a CAFO if there are 301-1,000 animal units confined in the facility, and it meets special criteria as defined by the NPDES-permitting authority. In addition, any AFO can be classified as a CAFO on a case-by-case basis if the NPDES-permitting authority determines that it is a significant contributor of pollution to the waters of the United States [ http://www.epa.gov/owm/afo.htm\#cafo ]. Following EPA terminology [ http://www.epa.gov/ owm/afoguide.htm ] we refer to "large operations" as those with greater than 1,000 AU and automatically subject to the NPDES permitting program.

2 According to the Unified National Strategy (USDA/USEPA), a CNMP contains the following components: feed management, manure handling and storage, land application of manure, record keeping, and other utilization options such as off-farm sales of manure and power generation. Our survey does not address the feed management or other options categories.

3 For the purposes of this research, "upstate" excludes the New York state counties of Nassau, Putnam, Orange, Suffolk, and Westchester and the five boroughs of New York City.

41996 data were used for milk production comparisons because the survey asked farmers to report their annual production for the previous year.

5 The broad extension of permits to cover operations with 301-1,000 AU is motivated by the general proximity of New York dairy farms to surface water and the Concerned Area Residents for the Environment v. Southview Farm ruling (CA 2, No. 93-9229, 9/2/94).

6 Consistent with federal water quality legislation, the AU data used here account for all animals on the farm, including those beyond the main milking herd (e.g., calves, heifers, other livestock). The 300 and $100 \mathrm{AU}$ thresholds correspond to 210 and 70 milking cows, respectively.

7 There were five responses to this survey from farms with more than 1,000 AU. These are deleted from the subsequent analyses, allowing us to focus on those farms presently outside the regulatory realm and only subject to voluntary programs.

8 Throughout, chi-square statistics associated with contingency table analyses are used for discrete variables and $F$-test statistics from ANOVA analyses are used for continuous variable unless otherwise indicated. A $p$ level of less than 0.10 indicates that the responses patterns across herd size groups are significantly different at the $10 \%$ level, and so on.

9 The upper bound of $\$ 100$ comes from early estimated costs associated with sequencing batch reactors designed to treat manure (personal communication with Carlos Montamagno, Agricultural and Biological Engineering School). Rowe, Schulze, and Breffle demonstrate that truncation effects are not a problem in payment cards if the upper end of the distribution is set at a sufficiently high level.

10 Because of the Cameron transformation, the bid value does not appear in the final regression. An indicator of the responsiveness of WTP to changes in this variable is provided in the coefficient on the $k$ variable in table 4 . In all cases, this coefficient was found to be highly significant, and thus, there is statistical evidence that farmers were responding to the variations in the costs of participation.

11 For this regression $n=357$ and $-2 \times \log$-likelihood $=1,869.48$.

\section{References}

Bills, N. L., and J. P. Cosgrove. “Agricultural Districts: Lessons from New York.” Dept. of Agricultural, Resource, and Managerial Economics, Staff Paper 98-01, Cornell University, 1998.

Blumenschein, K., M. Johannesson, G. C. Blomquist, B. Liljas, and R. M. O'Conor. "Experimental Results on Expressed Certainty and Hypothetical Bias in Contingent Valuation." S. Econ. J. 65 1(1998):169-177.

Cameron, T. A. "A New Paradigm for Valuing Non-Market Goods Using Referendum Data: Maximum Likelihood Estimation by Censured Logistic Regression." J. Env. Econ. Man. 15 (September 1988):355-379.

_ . "Interval Estimates of Non-Market Resource Values from Referendum Contingent Valuation Surveys." Land Economics 67 (November 1991):413-421. 
Cook, M., USEPA Statement to U.S. Congress Committee on Agriculture, Subcommittee of Forestry, Resource Conservation and Research and Subcommittee on Livestock, Dairy, and Poultry, "Activities of the Environmental Protection Agency Related to Livestock Feeding Operations." Joint Hearing 105th Congress, 2nd sess., May 13, 1998: 60. Serial No. 105-50.

Cooper, J. C., and R. W. Keim. "Incentive Payments to Encourage Farmer Adoption of Water Quality Protection Practices." Am. J. of Agr. Econ. 78 (February 1996):54-64.

Cooper, J. C., and C. T. Osborn. "The Effect of Rental Rates on the Extension of Conservation Reserve Program Contracts." Am. J. of Agr. Econ. 80 (February 1998):184-194.

Copeland, C., and J. Zinn. "Animal Waste Management and the Environmental: Background on Current Issues." CRS Report to Congress 98-451-ENR, Congressional Research Service, Washington, DC, 1999.

Daily, R. "Challenges for Agriculture: Do the Right Thing." Proceedings from the Nutrient Management Planning Conference. Nutrient Management Planning: Competitive Agriculture in Harmony with the Community, p. 1-13, Ontario Soil and Crop Improvement Association, Guelph, Ontario, 1999.

Heimlich R., and C. H. Bernard. Economics of Agricultural Management Practices in the Coastal Zone, USDAEcon. Res. Serv. Agr. Econ. Report 698, 1995.

Lohr, L., and T. A. Park. "Discrete/Continuous Choices in Contingent Valuation Surveys: Soil Conservation Decisions in Michigan." Rev. Agr. Econ. 16 (January 1994):1-15.

—. "Utility Consistent Discrete-Continuous Choices in Soil Conservation." Land Econ. 71 (November 1995):474-490.

Loomis, J. B., "18: Contingent Valuation Methodology and the US Institutional Framework." Valuing Environmental Preferences: Theory and Practice of the Contingent Valuation Method in the US, EU, and Developing Countries, pp. 613-627. I. J. Bateman and K. G. Willis, eds. Oxford: Oxford University Press, 1999.

McGuire, R. T. “A New Model to Reach Water Quality Goals.” Choices (2nd Quarter 1994):20-21, 24-25.

Mitchell, R. C., and R. T. Carson. Using Surveys to Value Public Goods: The Contingent Valuation Method. Washington DC: Resources for the Future, 1989.

Montemagno, C., Agricultural and Biological Engineering Department, Cornell University, Ithaca, NY, Personal Communication, 1997.

Moore, R. A. "Controlling Agricultural Nonpoint Source Pollution: The New York Experience." Drake Law Rev. 45 (1/1997):103-124.

New York Agricultural Statistics Service (NYASS). New York Agricultural Statistics 1996-1997. Albany, NY, July 1997.

Poe, G. L. “' Maximizing the Environmental Benefits per Dollar Expended': An Economic Interpretation and Review of Agricultural Environmental Benefits and Costs." Soc. Nat. Res. 12 (2/1999):571-598.

Poe, G. L., R. G. Ethier, M. P. Welsh, and W. D. Schulze. "Payment Certainty in Discrete Choice Contingent Valuation Responses: Results from a Field Validity Test." Selected paper presented at AAEA/ AERE Annual Meetings, Nashville TN, Aug. 1999. Abstract in Am. J. of Agr. Econ. 81 (December 1999):1295-1296.

Purvis, A., J. P. Hoehn, V. L. Sorenson, and F. J. Pierce. “Farmer Response to a Filter Strip Program: Results from a Contingent Valuation Survey." J. Soil Water Cons. 44 (November-December 1989):501-504.

Rowe, R. D., W. D. Schulze, and W. S. Breffle. "A Test for Payment Card Biases." J. Env. Econ. Man. 31 (September 1996):178-185.

Rudgers, N. First Deputy Commissioner, NYS Department of Agriculture and Markets, Personal Communication, 1998.

Samuelson, P.A. “The Pure Theory of Public Goods.” Rev. Econ. Stat. 36 (November 1954):350-356.

U.S. Department of Agriculture (USDA)/U.S. Environmental Protection Agency (USEPA). Unified National Strategy for Animal Feeding Operations, March 9, 1999, http://www.epa.gov/owm/finafost.htm 1999.

U.S. Environmental Protection Agency (USEPA). National Water Quality Inventory: 1996 Report to Congress, Washington, DC.

Welsh, M.P., and G.L. Poe. "Elicitation Effects in Contingent Valuation: Comparisons to a Multiple Bounded Discrete Choice Approach." J. Env. Econ. Man. 36 (September):170-185.

Wildeman, J. NYS Department of Agriculture and Markets, Personal Communication, 1998. 